\title{
Potencial de aproveitamento do coproduto da dieta de Diatraea saccharalis na
}

\section{alimentação de animais}

\author{
Potential for using the co-product of the Diatraea saccharalis diet in animal feed \\ Posibilidad de utilizar el coproducto de la dieta de Diatraea saccharalis en la alimentación animal
}

Roberto Balbino da Silva

ORCID: https://orcid.org/0000-0003-4105-7858 Universidade Federal da Paraíba, Brasil

E-mail: balbinorobert@ hotmail.com

Italo de Souza Aquino

ORCID: https://orcid.org/0000-0002-7948-8760 Universidade Federal da Paraíba, Brasil

E-mail: italo.aquino@terra.com.br

José Humberto Vilar da Silva

ORCID: https://orcid.org/0000-0001-8605-2829 Universidade Federal da Paraíba, Brasil

E-mail: vilardasiva@yahoo.com.br

Péricles de Farias Borges

ORCID: https://orcid.org/0000-0003-3585-1342 Universidade Federal da Paraíba, Brasil E-mail: pericles@cca.ufpb.br

Alex da Silva Barbosa

ORCID: https://orcid.org/0000-0002-7343-6134 Universidade Federal da Paraíba, Brasil E-mail: aldasibarbosa@cchsa.ufpb.br

\begin{abstract}
Resumo
A alimentação responde pelo maior custo de produção animal restringindo a margem de lucro dos criadores. O emprego de coprodutos na alimentação é vital não somente para viabilizar a produção animal, mas, também, mitigar a poluição ambiental e disponibilizar alimentos para animais em regiões não produtoras de grãos. O objetivo desse estudo foi avaliar o potencial nutricional do coproduto da dieta usada na criação de Diatraea saccharalis na alimentação animal. O delineamento experimental foi o inteiramente ao acaso com dois tratamentos e seis repetições, compostos pela dieta e sobras da dieta de $D$. saccharalis. As amostras foram homogeneizadas, moídas e analisadas para percentagens de matéria seca, umidade, proteína bruta, extrato etéreo, fibra bruta e matéria mineral. A energia bruta (kcal/kg) foi determinada em bomba calorimétrica tipo Parr. Os dados foram submetidos à análise de variância; médias foram comparadas pelo teste $\mathrm{F}(\mathrm{P}<0,05)$. Houve efeito significativo $(\mathrm{P}<0,05)$ para a maioria das variáveis, exceto a proteína bruta e o estrato etéreo. A percentagem de matéria seca do resíduo foi menor comparada ao percentual de matéria seca da dieta. Alterações na matéria seca ocorrem pelo aumento da umidade dos resíduos. Os valores de proteína bruta na matéria natural das amostras foram semelhantes aos valores de proteína do milho e bem abaixo do valor (proteína) do farelo de soja, indicando que esses ingredientes não substituem o farelo de soja nas dietas animais. O resíduo da dieta usada na criação da $D$. saccharalis tem potencial para aproveitamento em dietas de animais após secagem.
\end{abstract}

Palavras-chave: Broca-cana-de-açúcar; Nutrição animal; Dieta alternativa.

\begin{abstract}
Feeding is responsible for the higher cost of animal production, restricting the profit margin of breeders. The use of coproducts in food is vital not only to make animal production viable, but also to mitigate environmental pollution and make animal feed available in non-grain producing regions. The aim of this study was to evaluate the nutritional potential of the co-product of the diet used in the creation of Diatraea saccharalis in animal feed. The experimental design was completely randomized with two treatments and six replications, consisting of the diet and leftovers from the diet of $D$. saccharalis. The samples were homogenized, ground and analyzed for percentages of dry matter, moisture, crude protein, ether extract, crude fiber and mineral matter. Gross energy (kcal/kg) was determined in a Parr-type calorimetric pump. Data were subjected to analysis of variance; means were compared by the $\mathrm{F}$ test $(\mathrm{P}<0.05)$. There was a significant effect $(\mathrm{P}<0.05)$ for most variables, except for crude protein and ethereal stratum. The percentage of dry matter in the residue was lower compared to the percentage of dry matter in the diet. Changes in dry matter occur due to the increase in residue moisture. The crude protein values in the natural matter of the samples were similar to the corn protein values and well below the (protein) value of soybean meal, indicating that these ingredients do not replace
\end{abstract}


soybean meal in animal diets. The residue from the diet used in the creation of D. saccharalis has potential for use in animal diets after drying.

Keywords: Sugar cane borer; Animal nutrition; Alternative diet.

\section{Resumen}

La alimentación es responsable del mayor costo de la producción animal, restringiendo el margen de ganancia de los criadores. El uso de coproductos en los alimentos es vital no solo para viabilizar la producción animal, sino también para mitigar la contaminación ambiental y hacer que los alimentos para animales estén disponibles en las regiones no productoras de granos. El objetivo de este estudio fue evaluar el potencial nutricional del coproducto de la dieta utilizada en la creación de Diatraea saccharalis en la alimentación animal. El diseño experimental fue completamente al azar con dos tratamientos y seis repeticiones, consistente en la dieta y sobras de la dieta de $D$. saccharalis. Las muestras se homogeneizaron, molieron y analizaron en cuanto a porcentajes de materia seca, humedad, proteína cruda, extracto etéreo, fibra cruda y materia mineral. La energía bruta $(\mathrm{kcal} / \mathrm{kg}$ ) se determinó en una bomba calorimétrica tipo Parr. Los datos se sometieron a análisis de varianza; las medias se compararon mediante la prueba $\mathrm{F}(\mathrm{P}<0,05)$. Hubo un efecto significativo $(\mathrm{P}<0.05)$ para la mayoría de las variables, excepto para la proteína cruda y el estrato etéreo. El porcentaje de materia seca en el residuo fue menor en comparación con el porcentaje de materia seca en la dieta. Los cambios en la materia seca se producen debido al aumento de la humedad de los residuos. Los valores de proteína cruda en la materia natural de las muestras fueron similares a los valores de proteína de maíz y muy por debajo del valor (proteína) de la harina de soja, lo que indica que estos ingredientes no reemplazan la harina de soja en las dietas animales. El residuo de la dieta utilizada en la creación de $D$. saccharalis tiene potencial para su uso en dietas animales después del secado.

Palabras clave: Barrenador de la caña de azúcar; Nutrición animal; Dieta alternativa.

\section{Introdução}

Na produção animal, a alimentação é considerada, segundo Goes et al. (2013, p. 11), um desembolso essencial que pode chegar, em alguns casos, até $80 \%$ do custo de produção; e o conhecimento das propriedades dos novos alimentos é de fundamental importância para se obter uma ração balanceada e de baixo custo.

Segundo Silva (2009), dentre as alternativas para substituir o milho e farelo na ração animal destacam-se os coprodutos da agroindústria, disponíveis em algumas regiões do país, que ainda não foram avaliados na alimentação animal. O aproveitamento destes coprodutos pode diminuir a dependência da alimentação animal de rações industriais, que contem basicamente milho e farelo de soja com possibilidade de redução do custo de produção animal.

A Diatraea saccharalis é a principal praga da cana-de-açúcar no Brasil. Este inseto possui desenvolvimento holometabólico e na fase larval ocorre o maior prejuízo à cultura da cana-de-açúcar ao fazer galerias no colmo (Botelho et al., 1999).

Dentre os métodos de controle biológico da broca-da-cana, o braconídeo Cotesia flavipes é um dos mais eficientes (Vacari et al., 2012). No entanto, no processo de criação massal desse inseto benéfico, torna-se necessário produzir, também, o seu hospedeiro natural D. saccharalis em dieta artificial (Parra \& Mihsfeldt, 1992; Silva et al., 2021; Aquino et al., 2021). Essa dieta artificial deve suprir as exigências nutricionais para o pleno desenvolvimento do hospedeiro (Parra, 2012), preenchendo requisitos mínimos de qualidade biológica, quantidade e valor econômico acessível (Scriber \& Slansky, 1981; Salvadori \& Parra, 1990).

Após o final do ciclo de vida da $D$. saccharalis, os resíduos da dieta usada na sua criação são descartados e, muitas vezes, esses resíduos não recebem tratamento adequado antes de serem depositados no ambiente. Uma possível alternativa para mitigar esse problema ambiental seria destinar esses resíduos ao uso da alimentação animal. Desta forma, o uso desse coproduto na alimentação animal poder ser uma possibilidade de diminuir o custo de produção.

O objetivo desse estudo, de natureza quali-quantiva, foi avaliar o potencial de aproveitamento do subproduto da dieta usada na criação de Diatraea saccharalis na alimentação de animais. 


\section{Material e Métodos}

A pesquisa foi desenvolvida no Laboratório de Controle Biológico (LCB) da Associação de Plantadores de Cana da Paraíba (ASPLAN), localizado no município de Mamanguape, Paraíba, onde a dieta foi elaborada para a alimentação da Diatraea saccharalis. Posteriormente, amostras e sobras dessa dieta foram colhidas e levadas ao Laboratório de Nutrição Animal (LANA) da Universidade Federal da Paraíba (UFPB), no município de Bananeiras, Paraíba, para as determinações da composição química e de energia bruta.

O material coletado foi proveniente de uma dieta padrão utilizada na produção da $D$. saccharalis que serve de como hospedeiro para o desenvolvimento da $C$. flavipes, pequena vespa utilizada em programas de controle biológico da broca-dacana. A dieta utilizada pelo LANA é a proposta por Hensley \& Hammond (1968) e modificada pela ASPLAN (Tabela 1).

Tabela 1. Composição alimentar proposta da dieta usada na criação Diatraea saccharalis no Laboratório de Controle Biológico (LCB) da Associação de Plantadores de Cana da Paraíba (ASPLAN).

\begin{tabular}{lc}
\hline Ingrediente & $\%$ \\
\hline Farelo de soja & 7,284 \\
Gérmen de trigo & 4,669 \\
Açúcar & 5,229 \\
Nipagin & 0,280 \\
Ácido ascórbico & 0,075 \\
Cloreto de colina & 0,037 \\
Ácido sórbico & 0,140 \\
Carragena & 1,587 \\
Sais Welson & 0,747 \\
Solução vitamínica & 1,121 \\
Tetraciclina & 0,037 \\
Vita Gold & 0,037 \\
Formol & 0,037 \\
Ácido acético & 0,280 \\
Água (panela) & 41,087 \\
Água liquidificador & 37,352 \\
\hline Total & 100,000 \\
\hline
\end{tabular}

Fonte: Laboratório de Controle Biológico (LCB) da Associação de Plantadores de Cana da Paraíba (ASPLAN); Adaptação: Autores (2021).

Os tratamentos foram constituídos pela dieta (antes de seu fornecimento a $D$. saccharalis) a pelas sobras da dieta (após a alimentação dos insetos), totalizando 2 tratamentos com 6 repetições, representadas por seis amostras de lotes diferentes de dietas. Em seguida, as amostras foram estocadas em potes plásticos de $100 \mathrm{ml}$ com tampa, totalizando doze potes que, depois de homogeneizadas, foram moídas em moinho de facas tipo Willey e, posteriormente, submetidas as análises bromatológicas. Foram realizadas analises de matéria seca (MS), umidade (UM), energia bruta (EB), proteína bruta (PB), extrato etéreo (EE), fibra bruta (FB) e matéria mineral (MM), seguindo os procedimentos descritos por Silva e Queiroz (2002).

A energia bruta $(\mathrm{kcal} / \mathrm{kg})$ foi determinada em bomba calorimétrica modelo Parr, empregando $2 \mathrm{~g}$ de cada amostra colocada na cápsula de combustão, onde foi injetado oxigênio para queima da amostra, sendo o conteúdo energético de cada amostra aferido pelo equipamento e registrado. 
A matéria seca foi determinada pelo Método de Weende, um dos métodos químicos utilizados pela EMBRAPA (2010). Para a sua determinação, foi pesado $2 \mathrm{~g}$ da amostra em cadinhos de porcelana e previamente secos, por 2 horas, em estufa a 135 ${ }^{\circ} \mathrm{C}$. Em seguida, os cadinhos com as amostras foram levados para estufa de ventilação forçada e secos a $135{ }^{\circ} \mathrm{C}$, por 2 horas. Depois da secagem definitiva, os cadinhos foram acondicionados em dessecador por 2 horas até equilibrar com a temperatura do ambiente. Posteriormente, foram pesados para a aferição da matéria seca que foi determinada pela percentagem de perda de peso da amostra no processo de secagem. A umidade foi aferida através da subtração entre 100 e a matéria seca encontrada. A seguinte equação foi utilizada para determinação da matéria seca:

$$
\text { MS\% }=\frac{\text { Peso inicial }- \text { Peso final }}{\text { Peso inicial }} \times 100
$$

O extrato etéreo foi determinado pelo método quente de extração de lipídeos realizado através de Determinador de Gordura TE-044 - Goldfisch usando como solvente éter de petróleo. Foram pesados $2 \mathrm{~g}$ das amostras do material, moído e seco em cartuchos de papel filtro Whatman ${ }^{\circledR}$. Os cartuchos foram levados e acondicionados no extrator. Adicionou-se $40 \mathrm{ml}$ de éter de petróleo nos béqueres coletores. A amostras receberam a lavagem em banho maria, por 4 horas, numa velocidade de 6 gotas por segundo, a uma temperatura de $60^{\circ} \mathrm{C}$. Após a lavagem das amostras, estas foram secas em estufa a $105{ }^{\circ} \mathrm{C}$ por, 2 horas e, posteriormente, pesadas para a quantificação da gordura através da equação:

$$
\mathrm{EE} \%=\frac{\text { Peso inicial }- \text { Peso final }}{\text { Peso inicial }} \times 100
$$

Para a determinação da fibra bruta, as amostras secas e desengorduradas foram submetidas a digestões em aparelho digestor de fibras, onde estas amostras foram submetidas a digestões acidas e básicas. Para a digestão ácida foi utilizado a solução de ácido sulfúrico $\left(\mathrm{H}_{2} \mathrm{SO}_{4}-1,25 \%\right)$ e para a digestão básica foi usado hidróxido de sódio $(\mathrm{NaOH}-1,25 \%)$. Para a primeira digestão foi pesado $2 \mathrm{~g}$ de amostra e misturado com $200 \mathrm{ml}$ da solução de ácido sulfúrico e levado ao determinador de fibra a digestão. Esse procedimento teve a duração de 30 minutos; e, após a ebulição, o material digerido foi filtrado a vácuo em funil Buchner e lavado com água destilada até a neutralização do material. Em seguida, o material foi submetido a digestão básica com $200 \mathrm{ml}$ de hidróxido de sódio e o resíduo da digestão ácida, durante 30 minutos. Após a ebulição, o material foi filtrado, acondicionado em cadinho de porcelana e seco em estufa de ventilação forçada a $105{ }^{\circ} \mathrm{C}$ durante 6 horas. Estes foram pesados e levados para a mufla onde as amostras foram queimadas a $500{ }^{\circ} \mathrm{C}$ durante 2 horas. $\mathrm{O}$ conteúdo de fibra foi determinado em função da diferença de peso (peso da amostra inicial menos a amostra final).

Para a determinação da percentagem de proteína bruta, utilizou-se o Método de Kjeldahl, onde em tubos de ensaio foram pesados $500 \mathrm{mg}$ de amostra seca e adicionado: $2 \mathrm{~g}$ da mistura digestora e $10 \mathrm{ml}$ de ácido sulfúrico $\mathrm{H}_{2} \mathrm{SO}_{4}$. Em seguida, os tubos de ensaios foram levados ao bloco de aquecimento e submetidos a uma temperatura de $350{ }^{\circ} \mathrm{C}$; a digestão durou cerca de 4 horas até se obter solução clara. Após o resfriamento, os tubos foram levados ao destilador de nitrogênio, onde adicionou-se $20 \mathrm{ml}$ de hidróxido de sódio $(\mathrm{NaOH})$ e, em outro tubo (Erlenmeyer), foi colocado $50 \mathrm{ml}$ de ácido bórico $\left(\mathrm{H}_{3} \mathrm{BO}_{3}\right)$. Esta solução, após destilação, teve o nitrogênio capturado pela solução de ácido bórico e titulado com ácido clorídrico $(\mathrm{HCl})$ até a mudança de verde para rosa. O conteúdo de proteína foi determinado através da seguinte equação:

$$
P B \%=\frac{[(V-v) \times F c \times N \times 6,25 \times 0,014]}{P} X 100
$$


$\mathrm{V}=$ Volume de $\mathrm{HCl}$ gasto na titulação

$\mathrm{v}=$ Volume de $\mathrm{HCl}$ gasto na titulação do teste branco

$\mathrm{Fc}=$ Fator de correção do $\mathrm{HCl} 0,1 \mathrm{~N}$

$\mathrm{N}=$ Normalidade

$\mathrm{P}=$ Peso da amostra

6,25 = Fator de conversão de nitrogênio em proteína

$0,014=$ Miliequivalente grama do nitrogênio

A matéria mineral foi determinada através da queima das amostras em mufla a $600{ }^{\circ} \mathrm{C}$, sendo inicialmente pesado as amostras em cadinhos de porcelana. Estes foram levados para a mufla e incinerados por 5 horas até se obter cinza clara, evidenciando a queima dos compostos orgânicos. Após o resfriamento das amostras, estas foram novamente pesadas e, por diferença de peso, foi calculado a percentagem de minerais através da equação:

$$
M M=\frac{\text { Peso inicial }- \text { Peso final }}{\text { Peso incial }} \times 100
$$

Os resultados coletados, com base no método científico indutivo, para um diagnóstico da magnitude dos efeitos (Lakatos \& Marconi, 2003; Pereira et al., 2018), foram submetidos a análise estatística, mediante análise de variância (ANOVA). Tendo em vista o número de tratamentos igual a dois, as médias foram comparadas através do teste de $\mathrm{F}$ a $5 \%$ de probabilidade. Foi coletado dados de composição nutricional de milho e de farelo de soja e realizou-se a comparação numérica entre seus teores nutricionais com os materiais do estudo.

\section{Resultados e Discussão}

Os resultados de composição química da dieta e do resíduo utilizado na criação da Diatraea saccharalis estão representados na Tabela 2. Exceto os teores de proteína, extrato etéreo e matéria mineral que foram semelhantes entre os dois tratamentos, os teores de matéria seca, energia bruta e fibra apresentaram diferenças significativas $(\mathrm{P}<0,05)$ entre a sobra e a dieta dos insetos.

Tabela 2. Composição química na matéria natural da dieta e do resíduo utilizado na criação da Diatraea saccharalis.

\begin{tabular}{lcrcc}
\hline \multirow{2}{*}{ Composição química } & \multicolumn{2}{c}{ Alimentos \pm Erro padrão } & \\
\cline { 2 - 5 } & \multicolumn{1}{c}{ Dieta } & \multicolumn{1}{c}{ Resíduo } & CV\% & P-value \\
\hline Matéria seca (\%) & $42,25 \pm 0,095^{\mathrm{a}}$ & $41,77 \pm 0,105^{\mathrm{b}}$ & 0,58 & 0,007 \\
Umidade (\%) & $57,74 \pm 0,095^{\mathrm{b}}$ & $58,22 \pm 0,105^{\mathrm{a}}$ & 0,42 & 0,007 \\
Energia bruta (Kcal/Kg) & $1379,59 \pm 11,130^{\mathrm{a}}$ & $1329,29 \pm 5,242^{\mathrm{b}}$ & 1,57 & 0,002 \\
Extrato etéreo (\%) & $8,47 \pm 0,193^{\mathrm{a}}$ & $8,89 \pm 0,096^{\mathrm{a}}$ & 4,32 & 0,085 \\
Proteína bruta (\%) & $9,43 \pm 0,416^{\mathrm{a}}$ & $9,55 \pm 0,340^{\mathrm{a}}$ & 8,39 & 0,925 \\
Fibra bruta (\%) & $1,80 \pm 0,339^{\mathrm{b}}$ & $2,52 \pm 0,398^{\mathrm{a}}$ & 18,45 & 0,004 \\
Material mineral (\%) & $2,16 \pm 0,153^{\mathrm{a}}$ & $2,46 \pm 0,058^{\mathrm{a}}$ & 12,22 & 0,092 \\
\hline
\end{tabular}

$\mathrm{ab}=$ Médias seguidas de letras diferentes na linha diferem pelo teste de $\mathrm{F}$ a $5 \%$ de probabilidade;

CV\%=Coeficiente de variação; $P$-value $=$ Probabilidade de significância.

Fonte: Autores (2021). 
A percentagem de matéria seca da sobra diminui em comparação a matéria seca da dieta antes da oferta aos insetos. O aumento da umidade da sobra ocorreu pelo consumo seletivo do material sólido da dieta pelos insetos, considerando que a dieta continha alto teor de umidade. Portanto, a menor matéria seca da sobra é explicada pela necessidade de os insetos retirarem da dieta os nutrientes em taxas adequadas ao seu desenvolvimento. De acordo com a classificação de Weende, o alimento é constituído de matéria seca e umidade, estando os nutrientes presentes na matéria seca dos alimentos), que explica a diminuição da matéria seca do resíduo, pois uma percentagem da dieta foi consumida pelos insetos.

A energia bruta é a energia potencial resultante da combustão dos componentes orgânicos do alimento como proteína, lipídeos e carboidratos. A energia bruta foi maior na dieta antes da oferta aos insetos comparada a sobra $(\mathrm{P}<0,05)$. Apesar dos conteúdos de proteína e de extrato etéreo não terem sido alterados nas duas frações, sobra e dieta, pelos insetos, presume-se que a maior energia bruta da dieta foi causada pela grande proporção de açúcar $(5,23 \%)$ na dieta, assegurando, desta forma, um valor de energia bruta mais para a dieta.

A dieta utilizada pelo LCB, em seu programa de controle biológico, é composta de vários ingredientes, alguns sem nenhuma contribuição ao valor nutritivo da mistura e, outros, como o farelo de soja, gérmen de trigo ofertando, respectivamente, proteína, lipídeos e carboidratos. Entretanto, parece que os insetos preferem consumir mais os carboidratos da dieta, o que corrobora a explicação que a menor energia bruta da sobra em relação à dieta foi motivada pelo consumo seletivo do açúcar pelos insetos. É importante realçar que esses insetos, na natureza, se alimentam no interior dos colmos da cana-de-açúcar (Furtado, 2016, p. 21) o que, desta forma, ajuda a explicar a falta de efeito significativo entre os conteúdos de proteína e de extrato etéreo entre os materiais.

Os teores de fibra bruta e minerais aumentaram no resíduo, o que pode ser explicado pelo comportamento de ingesta dos insetos, os quais demonstram preferência pelos carboidratos. Mesmo a dieta sendo confeccionada de forma padrão, sem haver modificações de quantidades de ingredientes, o fato da preferência do consumo de carboidratos elevou a percentagem de fibra bruta e de matéria mineral no resíduo.

Na Tabela 3 estão apresentados os dados de composição química centesimal da dieta e do resíduo, em comparação a dois ingredientes utilizados em dietas de alimentação de animais de produção.

Tabela 3. Composição química na matéria natural da dieta utilizada na criação massal de Diatraea saccharalis e do seu resíduo em comparação a composição de dois ingredientes usados na alimentação animal.

\begin{tabular}{lrccc}
\hline \multirow{2}{*}{ Composição química } & \multicolumn{4}{c}{ Alimentos } \\
\cline { 2 - 5 } & Dieta & Resíduo & Farelo de Soja & Milho \\
\hline Matéria seca (\%) & 42,25 & 41,77 & 89,60 & 88,90 \\
Umidade (\%) & 57,75 & 58,23 & 10,40 & 11,10 \\
Energia bruta (Kcal/Kg) & 1379,59 & 1329,29 & 4118,00 & 3901,00 \\
Extrato etéreo (\%) & 8,47 & 8,89 & 1,95 & 3,81 \\
Proteína bruta (\%) & 9,43 & 9,56 & 45,40 & 7,86 \\
Fibra bruta (\%) & 1,80 & 2,52 & 4,86 & 1,73 \\
Matéria mineral (\%) & 2,16 & 2,47 & 5,66 & 1,11 \\
\hline
\end{tabular}

Fonte: Autores (2021).

A matéria seca dos materiais são inferiores a materia seca do milho e do farelo de soja. Os animais de produção exigem dietas que tenham determinadas quantidades de matéria seca, pois é na matéria seca que estão contidos os nutrientes exigidos pelos animais; alimentos com baixo teor de matéria seca indicam baixo teor de nutrientes. Segundo (Mertens, 1994), dentre todas as tecnologias e estratégias criadas para aumentar o desempenho dos animais, nenhuma é tão eficaz e importante quanto o 
consumo de matéria seca digestível. Isso porque, animais que não consomem o que necessitam, diariamente, não satisfazem totalmente as exigências para ganho de peso e, em situações mais drásticas, nem mesmo para mantença. O baixo teor de matéria seca pode indicar menor percentagem de alimentos sólidos em determinada dieta e maior infestação de microrganismos patogênicos que danificam a composição nutricional do alimento.

Os alimentos recebem classificação nutricional de acordo com as concentrações de determinados nutrientes em sua composição. O teor de fibra, por exemplo, indica se o alimento é concentrado ou volumoso. Alimento com mais de $18 \%$ de fibra na sua composição é considerado volumoso e com menos de $18 \%$ considerado como concentrado (EMBRAPA, 1996). A dieta estudada apresentou menos de 18\% de fibra em sua estrutura, portanto a dieta é um alimento concentrado; seu teor de fibra é semelhante ao teor de fibra do milho, mas o teor de fibra do resíduo foi moderadamente superior. A fibra é um componente importante da dieta de ruminantes, sendo fonte de energia na forma de ácidos graxos voláteis para o metabolismo celular, através da fermentação microbiana no rúmen. Já para os não ruminantes, a fibra atua como redutor do tempo de passagem do alimento no intestino e, com o aumento da viscosidade intestinal, piora o aproveitamento de nutrientes dos alimentos.

O teor de proteína do alimento serve como parâmetro de classificação nutricional de um alimento. Os alimentos concentrados podem ser classificados em proteicos e energéticos. Os concentrados proteicos possuem mais de $20 \%$ de proteína bruta na matéria seca; já os energéticos possuem menos de $20 \%$ de proteína bruta. Tanto a dieta quanto o seu resíduo possuem mais de $20 \%$ de proteína bruta na matéria seca, o que os caracterizam como concentrados proteicos.

\section{Conclusão}

O resíduo da dieta usada na criação da Diatraea saccharalis tem potencial para aproveitamento na alimentação animal na forma seca.

Estudos adicionais são necessários para se determinar que espécies de animais, incluindo animais pets, podem ser alimentados com o resíduo da dieta da $D$. saccharalis.

\section{Agradecimentos}

Aos técnicos do Laboratório de Controle Biológico (LCB) da Associação de Plantadores de Cana da Paraíba (ASPLAN) pelo fornecimento do material utilizado nesta pesquisa.

\section{Referências}

Aquino, I. S., Silva, R. B., Borges, P. F., Barbosa, A. S. \& Medeiros, G. R. (2021). Aspectos comportamentais do hospedeiro Diatraea saccharalis produzidos em laboratório. Research, Society and Development, 10(5): 1-7. http://dx.doi.org/10.33448/rsd-v10i5.13507

Botelho, P. S. M., Parra, J. R., Chagas Neto, J. F. C. \& Oliveira, C. P. (1999). Associação do parasitoide de ovos Trichogramma galloi Zucchi (Hymenoptera: Trichogrammatidae) e do parasitoide larval Cotesia flavipes (Cam.) (Hymenoptera: Braconidae) no controle de Diatraea saccharalis (Fabr.) (Lepidoptera: Crambidae) em cana-de-açúcar. Anais da Sociedade Entomológica do Brasil, 28(3), 491-496.

Empresa Brasileira de Pesquisa Agropecuária - EMBRAPA. (1996). In: Cardoso, E. G. (1996). Engorda de bovinos em confinamento - aspectos gerais. EMBRAPA. http://old.cnpgc.embrapa.br/publicacoes/doc/doc64/index.html.

Empresa Brasileira de Pesquisa Agropecuária - EMBRAPA. (2010). In: Salman, A. K. D, Ferreira, A. C. D., Soares, J. P. G. \& Souza, J. P. Metodologias para avaliação de alimentos para ruminantes domésticos. Porto Velho: EMBRAPA. https://www.infoteca.cnptia.embrapa.br/bitstream/doc /884369/1/doc136ali mentacaoderuminantes.pdf.

Furtado, V. L. (2016). Controle biológico da Diatraea saccharalis na cultura da cana-de-açúcar no município de Frutal-MG. Frutal: Prospectiva, 51 p. https://www.aacademica.org/repositorio.digital.uemg.frutal/63.pdf.

Tonissi, R. H., Goes, B., Silva, L. H. X. \& Souza, K. A. (2013). Alimentos e alimentação animal. Universidade Federal da Grande Dourados. Dourados: Editora UFGD, 79 p. http://nbcgib.uesc.br/ppgca/files/docentes_processo_seletivo/alimentos_e_alimentacao_animal.pdf

Hensley, S. D. \& Hammond, A. H. (1968). Laboratory techniques for rearing the sugar cane borer on an artificial diet. Journal of Economic Entomology. 61(6), 1742-1743. https://doi.org/10.1093/jee/61.6.1742 
Lakatos, E. M. \& Marconi, M. A. (2003). Fundamentos de metodologia científica. (5a ed.), Atlas, 225 p.

Macedo, N. (2000). Método de criação do parasitoide Cotesia flavipes (Cameron, 1981).: In Bueno, V. H. P. (Ed.). Controle biológico de pragas: produção massal e controle de qualidade. UFLA, cap. 9, p. 161-166 e 172.

Mertenes, D. R. (1994). Regulation of forage intake. In: Fahey JR., G. C. (Ed.) Forage quality, evaluation and utilization. Winsconsin: American Society of Agronomy, 450-493.

Parra, J. R. P. (2012). The evolution of artificial diets and their interactions in science and technology. In: Panizzi, A. R.; Parra, J. R. P. (Eds.) Insect bioecology and nutrition for integrated pest management. Boca Ratón: CRC Press, p. 51-92.

Parra, J. R. P. \& Mihsfeldt, L. H. (1992). Comparison of artificial diets for rearing the sugarcane borer. In: Anderson, T. E.; Leppla, N. C. (Ed.). Advances in insect rearing for research and pest management. Westview Press, p.195-209.

Parra, J. R. P., Milano, P., Consoli, F. L., Zerio, N. G. \& Haddad, M. L. (1999). Efeito da nutrição de adultos e da umidade na fecundidade de Diatraea saccharalis (Fabr.) (Lepidoptera: Crambidae). Anais da Sociedade Entomológica do Brasil. 28(1): 49-57. https://doi.org/10.1590/S0301-80591999000100005

Pereira, A. S., Shitsuka, D. M., Parreira, F. J. \& Shitsuka, R. (2018). Metodologia da pesquisa científica. UFSM. https://repositorio.ufsm.br/bitstrea $\mathrm{m} /$ handle/1/158 24/Lic_Comp utacao_Metodologia-Pesquisa-Cientifica.pdf?sequence=1

Salvadori, J. R. \& Parra, J. R. P. (2001). Seleção de dietas artificiais ara Pseudaletia sequax (Lep.: Noctuidae). In: Bavaresvo, A., Garcia, M. S., Grützmacher, A. D., Foresti, J. \& Ringenberg, R. Efeito de fontes de carboidratos sobre o desempenho reprodutivo de Spodoptera cosmioides (Walk., 1858) (Lepidoptera: Noctuidae) Revista Brasileira de Agrociência, 7(3): 177-180.

Silva, D. J. \& Queiroz, A. C. (2002). Análises de alimentos - Métodos químicos e biológicos. (3a ed.), UFV, 235 p.

Silva, J. H. V. (2019). Ingredientes de rações para codornas. In: Silva, J. H. V., \& Costa, F. G. P. Tabelas para codornas japonesas e europeias. Jaboticabal: Ed. Funep, p. 25-41.

Silva, R. B., Aquino, I. S., Borges, P. F., Barbosa, A. S. \& Medeiros, G. R. (2021). Aspectos comportamentais do parasitóide Cotesia flavipes produzido em laboratório no litoral norte paraibano. Research, Society and Development, 10(2): 1-13. http://dx.doi.org/10.33448/rsd-v10i2.12666

Scriber, J. M. \& Slansky Jr. The nutritional ecology of immature insects. (1981). Revisão Anual da Entomologia, $26: 183-211$.

Vacari, A. M., De Bortoli, S. A. \& Torres, J. B. (2012). Relation between predation by Podisus nigrispinus and developmental phase and density of its prey, Plutella xylostella. Entomologia Experimentalis et Applicata, 145(1): 30-37. 